\title{
Sistem Informasi Geografis Apotek di Kotawaringin Timur Berbasis Web
}

\author{
Nur Rachmat Fajar Ramadhani, Eka Prasetyaningrum, Lukman Bachtiar \\ Fakultas Ilmu Komputer, Jurusan Sistem Informasi, Universitas Darwan Ali, Sampit, Indonesia \\ Email: ${ }^{1}$ rachmat.fajar98@gmail.com, ${ }^{2}$ ekatya94@gmail.com, ${ }^{3}$ lukmanbachtiar.unda@gmail.com
}

\begin{abstract}
Abstrak
Sistem Informasi Geografis adalah sistem informasi yang di khususkan mengolah data yang memiliki informasi spasial (bereferensi keruangan). Dalam artian lebih sempit sistem informasi geografis adalah sistem komputer yang mempunyai kemampuan untuk membangun, menyimpan, mengelola dan menampilkan informasi berefrensi geografis, dimisalkan data yang diidentifikasi menurut lokasinya dalam sebuah database. Tujuan sistem informasi geografis ini adalah untuk mengetahui informasi akan letak persebaran Apotek dan informasi data obat di Kotawaringin Timur, sehingga membantu masyarakat maupun masyarakat yang bukan asli dari Kotawaringin Timur. Pembuatan sistem informasi geografis apotek di Kotawaringin Timur berbasis web ini menggunakan bahasa pemrograman PHP dan MySQL sebagai sistem database.
\end{abstract}

Kata Kunci: Sistem Informasi; Geografis; Apotek; PHP; MySQL

\section{Abstract}

Geographical Information System is an information system that is specialized in processing data that has spatial information (spatial reference). In a narrower sense, a Geographical Information System is a computer system that has the ability to build, store, manage and display geographic information, for example, data that is identified according to its location in a database. The purpose of this geographic information system is to find out information on the location of the distribution of pharmacies and drug data information in East Kotawaringin, so as to help people and people who are not native to East Kotawaringin. The development of a web-based pharmacy geographic information system in East Kotawaringin uses the programming language PHP and MySQL as the database system.

Keywords: Information Systems; Geographical; Pharmacy; PHP; MySQL

\section{PENDAHULUAN}

Di zaman yang sudah maju saat ini teknologi sistem informasi dan internet sudah tidak lagi menjadi hal istimewa. Internet sudah menjadi hal yang biasa dan menjadi sebuah kebutuhan sehari-hari dalam segala bidang. Internet juga menyediakan segala akses informasi yang sangat banyak dan tidak terbatas dan juga murah. Tetapi, sangat banyak pengguna yang tidak menggunakan internet dengan tidak benar dan cerdas. Yang dimaksud dengan cerdas adalah menuju pada penggunaan internet yang digunakan dengan tepat, sehat dari segi konten, produsen dan konsumen.

Teknologi informasi pada saat ini sudah memasuki hampir seluruh sudut kehidupan. Teknologi dibuat bertujuan untuk meringankan pekerjaan manusia yang tadinya rumit menjadi lebih mudah dan sederhana. Web adalah merupakan salah satu hasil dari pemanfaatan teknologi yang memugkinkan hampir semua orang mengakses informasi dimanapun dan kapanpun mereka berada selama mereka terhubung ke jaringan terutama internet. Web adalah saran untuk antar muka informasi di internet yang bisa menggabungkan teks, grafik dan multimedia dengan metode navigasi menu, web adalah sekelompok kode berbasis teks yang sederhana dan universal, disebut Hypertext Markup Language (HTML).

Sistem Informasi Geografis adalah sistem informasi yang di khususkan mengolah data yang memiliki informasi spasial (bereferensi keruangan). Dalam artian lebih sempit Sistem Informasi Geografis adalah sistem komputer yang mempunyai kemampuan untuk membangun, menyimpan, mengelola dan menampilkan informasi berefrensi geografis, dimisalkan data yang diidentifikasi menurut lokasinya dalam sebuah database.

Apotek adalah adalah tempat menjual dan kadang membuat atau meramu obat. Apotek juga merupakan tempat apoteker melakukan praktik profesi farmasi sekaligus menjadi peritel. Kata Apotek berasal dari Bahasa Yunani Apotecha yang secara harfiah dengan arti "penyimpanan".

Di kabupaten Kotawaringin Timur terdapat banyak apotek-apotek yang ada. Namun dengan jumlah apotek yang banyak tanpa informasi yang relevan dan akurat mengenai tata letak dan lokasi persebarannya justru menimbulkan kebingungan dan ketidakjelasan bagi masyarakat di Kotawaringin Timur. Pencarian apotek dilakukan dengan berkendara untuk mencari lokasi apotek terdekat, dan apabila apotek tidak ditemukan maka masyarakat akan mencari apotek terdekat yang lain dengan cara berkendara sampai menemukan apotek tedekatnya. Kesulitan menemukan lokasi apotek sering terjadi sehingga mengakibatkan sejumlah apotek tidak dapat memenuhi kebutuhan masyarakat, menghambat masyarakat dalam mendapatkan obat yang diperlukan dengan cepat dan sisi lainnya juga dapat menyebabkan rendahnya daya saing dengan apotek lainnya.

Menurut Julianti, dkk (2018) menyebutkan dalam jurnal bahwa di kota Bogor terdapat banyak apotekapotek yang ada, tetapi informasi keberadaan apotek tersebut kurang diketahui masyarakat dalam mencari letak apotek yang terdekat. Keterbatasan informasi mengenai apotek tersebut dapat menghambat masyarakat dalam mendapatkan obat yang diperlukan dengan cepat [1]. 
Dalam hal ini diperlukan Sistem Informasi Geografis (GIS) pencarian apotek di wilayah Kotawaringin Timur yang dapat mengetahui berapa banyak apotek, titik lokasi dan dapat menampilkan detail informasi apotek untuk masyarakat Kotawaringin Timur maupun masyarakat yang bukan asli dari Kotawaringin Timur.

\section{METODE PENELITIAN}

\subsection{Tahapan Penelitian}

Metode penelitian pada penelitian ini dilakukan beberapa tahap seperti penjelasan di bawah ini :

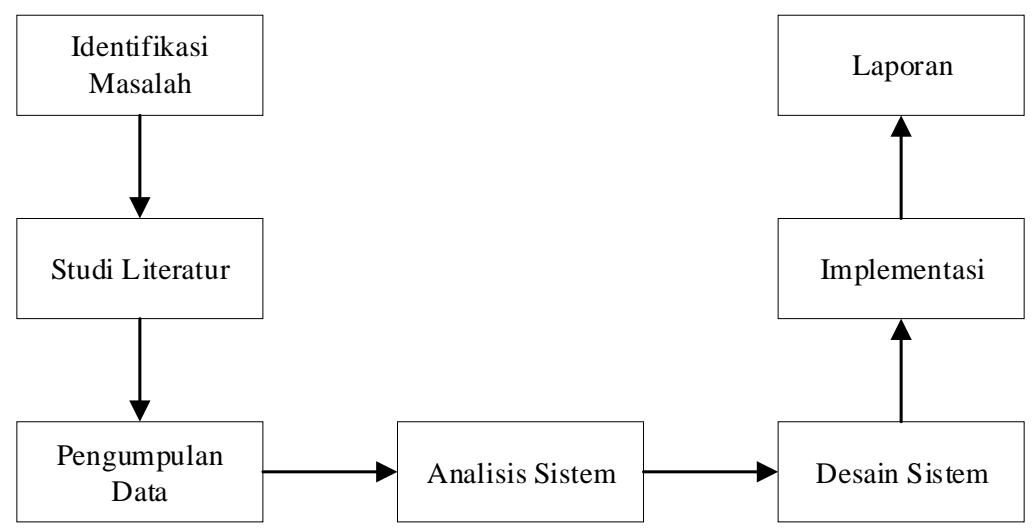

Gambar 1. Tahap-Tahap Penelitian

Langkah-langkah dalam penelitian ini meliputi tahapan-tahapan sebagai berikut :

1. Identifikasi Masalah

Pada tahap identifikasi masalah diharapkan penulis dapat mengerti masalah yang diteliti. Tahap awal identifikasi masalah adalah merumuskan masalah agar penelitian ini dapat berjalan terarah dan teratur sesuai dengan masalah yang diteliti.

2. Studi Literatur

Pada tahap ini penulis mempelajari teori-teori dasar yang mendukung pengembangan sistem yang berasal dari materi-materi yang sudah ada baik berupa buku, jurnal, website dan lain sebagainya yang ada hubungannya dengan penelitian ini. Dengan mempelajari teori-teori tersebut, maka penulis akan lebih memahami bagaimana mengembangkan sistem dengan lebih baik.

3. Pengumpulan Data

Dalam memperoleh data menggunakan 2 teknik, yaitu :

a. Wawancara

Wawancara merupakan metode pengumpulan data dengan jalan Tanya jawab sepihak yang dilakukan secara sistematis dan berlandaskan kepada tujuan penelitian.

b. Observasi

Observasi sebagai suatu metode pegumpulan data dengan cara mengamati perilaku dan lingkungan (sosial/material) individu yang sedang diamati.

4. Analisis Sistem

Analisis sistem merupakan aktivitas mengidentifikasi, mengevaluasi permasalahandan kebutuhan yang diharapkan. Analisis sistem berkaitan dengan objek-objek lokasi geografis apotek untuk mendukung penelitian. Adapun data yang dianalisis untuk dirancang sebagai sistem adalah data yang berhubungan dengan keberadaan apotek, perlunya titik koordinat apotek tempat apotek-apotek berada lalu alamat lengkap tentang apotek dan kemudian ditambah gambar tentang lokasi apotek dari data-data ini harus dimappingkan terlebih dahulu, sehingga data-data tersebut dapat dijadikan landasan untuk perancangan sistem informasi geografis apotek.

5. Desain Sistem

Pada tahap ini, penulis membuat desain dari model sistem dengan menggunakan beberapa alat bantu untuk menggambar sistem yang berjalan ataupun sistem baru yang akan dikembangkan secara logika. Untuk proses fungsi yang akan dilakukan sistem dan kebutuhan data menggunakan use case diagram, Activity Diagram, Sequence Diagram, dan Class Diagram.

6. Implementasi

Tahap implementasi ini di mana apakah fungsi dari website sudah berjalan dan bisa digunakan.

7. Laporan

Pada tahap ini dilakukan pembuatan laporan penelitian yang berisi kesimpulan dan saran-saran yang baik. 


\subsection{Apotek}

Apotek merupakan sarana pelayanan kefarmasian tempat dilakukan praktek kefarmasian oleh apoteker untuk menjamin mutu pelayanan kefarmasian di apotek, maka harus dilakukan evaluasi mutu pelayananan kefarmasian. Di era globalisasi saat ini, persaingan apotek yang berasal dari dalam negeri maupun pemilik sarana apotek Masyarakat Ekonomi ASEAN (MEA) yang masuk ke Indonesia semakin tak terelakkan. Selain itu, deregulasi tentang pendirian apotek, tingginya permintaan konsumen terhadap obat dan banyaknya jumlah apoteker juga menjadi faktor pemicu semakin banyaknya jumlah apotek. Secara tidak langsung, persaingan bisnis antar apotek semakin ketat demi memperoleh jumlah pelanggan semaksimal mungkin [2].

\subsection{Teknologi}

Kata teknologi berasal dari bahasa Yunani, technologia, techne yang berarti 'keahlian' dan logia yang berarti 'pengetahuan'. Teknologi mengacu pada objek benda yang dipergunakan untuk memudahkan aktivitas manusia, seperti mesin, perkakas atau perangkat keras. Kata teknologi secara harfiah berasal dari bahasa latin 'texere' yang berarti menyusun atau membangun, sehingga istilah teknologi seharusnya tidak terbatas pada penggunaan mesin, meskipun dalam arti sempit hal tersebut sering digunakan dalam kehidupan sehari-hari. Teknologi sebagai alat yang digunakan oleh individu untuk membantu menyelesaikan tugas-tugas mereka. Dalam penelitian sistem informasi, teknologi merujuk pada sistem komputer yang terdiri dari perangkat keras, perangkat lunak dan data serta dukungan layanan yang disediakan untuk membantu para pemakai dalam menyelesaikan tugasnya [3], [4].

\subsection{Sistem Informasi}

Sistem informasi yaitu suatu sistem yang menyediakan informasi untuk pemasaran dan juga untuk menjalankan operasional perusahaan, di mana sistem tersebut merupakan kombinasi dari orang-orang, teknologi informasi dan prosedur-prosedur yang terorganisasi [5], [6].

\subsection{Sistem Informasi Geografis}

Sistem Informasi Geografis (SIG) merupakan suatu sistem informasi berbasis komputer untuk menyimpan, mengelola dan menganalisis, serta memanggil data bereferensi geografis [7]. Sistem informasi geografis mulai dikenal pada awal 1980-an. Sejalan dengan berkembangnya perangkat komputer, baik perangkat lunak maupun perangkat keras, SIG berkembang mulai sangat pesat era 1990-an dan saat ini mulai berkembang. Komponen kunci dalam SIG adalah sistem komputer, data geospatial (data atribut) dan pengguna.

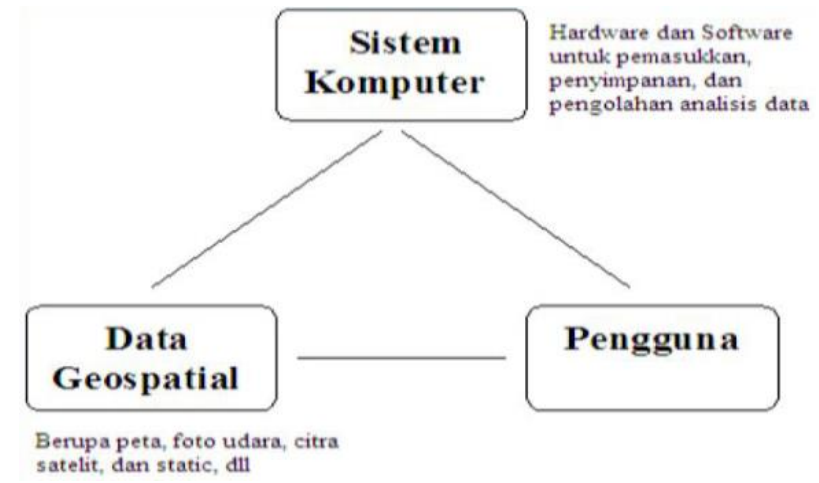

Gambar 2. Komponen Utama Sistem Informasi Geografis (SIG)

\subsection{Peta}

Peta merupakan gambaran permukaan bumi yang diperkecil, dituangkan dalam selembar kertas atau media lain dalam bentuk dua dimensi. Melalui sebuah peta kita akan mudah dalam melakukan pengamatan terhadap permukaan bumi yang luas, terutama dalam hal waktu dan biaya [8].

\subsection{Unified Modelling Language (UML)}

Unified Modeling Language (UML) adalah bahasa spesifikasi standar yang dipergunakan untuk mendokumentasikan, menspesifikasikan dan membangun perangkat lunak. UML merupakan metodologi dalam mengembangkan sistem berorientasi objek dan juga merupakan alat untuk mendukung pengembangan sistem [9].

1. Use Case Diagram

Use Case Diagram merupakan pemodelan untuk kelakuan (behavior) sistem informasi yang akan dibuat. Use case digunakan untuk mengetahui fungsi apa saja yang ada di dalam sistem informasi dan siapa saja yang berhak menggunakan fungsi-fungsi tersebut.

2. Activity Diagram

Activity Diagram menggambarkan workflow (aliran kerja) atau aktivitas dari sebuah sistem atau proses bisnis.

3. Sequence Diagram 
Sequence Diagram menggambarkan kelakuan objek pada use case dengan mendepenelitiankan waktu hidup objek dan pesan yang dikirimkan dan diterima antar objek.

4. Class Diagram

Class Diagram merupakan hubungan antar kelas dan penjelasan detail tiap-tiap kelas di dalam model desain dari suatu sistem, juga memperlihatkan aturan-aturan dan tanggung jawab entitas yang menentukan perilaku sistem.

\section{ANALISA DAN PEMBAHASAN}

Berdasarkan dari permasalahan yang telah dijabarkan sebelumnya maka dapat dibuat analisis kebutuhan sistem yang dapat menjadi solusi ataupun usulan bagi perbaikan dari permasalahan-permasalahan serta kendala-kendala yang terjadi pada sistem informasi pencarian apotek yang berjalan saat ini di Kotawaringin Timur. Tahap ini merupakan salah satu tahap yang penting, karena kesalahan dalam mengidentifikasikan permasalahan dalam sistem akan menimbulkan salah persepsi ketika ingin merancang sistem. Hal ini akat berakibat pada kurang akuratnya perancangan yang dibuat. Sistem yang berjalan saat ini masih dengan cara pencarian manual yaitu dengan cara pencarian apotek di Kotawaringin Timur berkendara untuk mencari lokasi apotek terdekat, dan apabila apotek tidak ditemukan maka masyarakat akan mencari apotek terdekat yang lain dengan cara berkendara sampai menemukan apotek tedekatnya. Cara ini sangat tidak efisien karena menghabiskan banyak waktu, tenaga dan juga bahan bakar kendaraan.

\subsection{Desain Sistem}

Tahapan perancangan memiliki tujuan untuk mendesain sistem baru yang dapat menyelesaikan masalah-masalah yang dihadapi, diperoleh dari pemilihan alternatif sistem yang baik. Dari hasil analisis dan deskripsi sistem diatas telah diketahui kelemahan sistem tersebut, maka sistem yang ada harus diperbaiki dan dibuat rancangan sistem yang baru.

\section{Use Case Diagram}

Use Case Diagram adalah konstruksi untuk mendeskripsikan bagaimana sistem terlihat dimata pengguna.

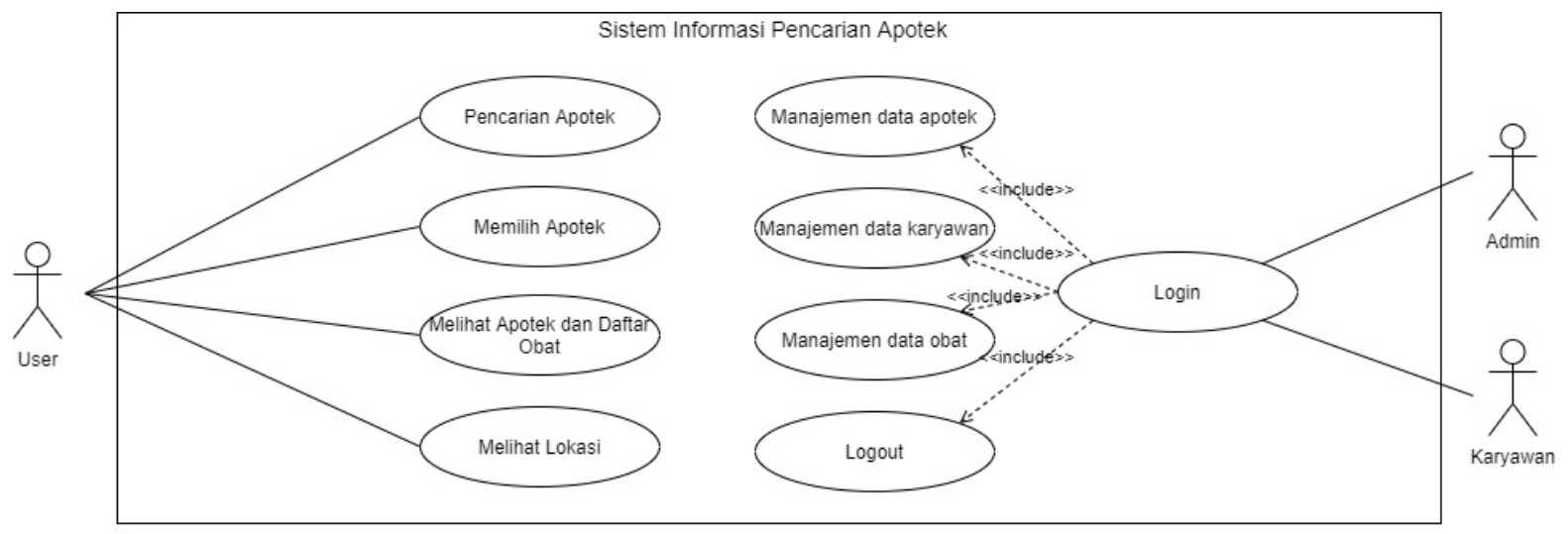

Gambar 3. Use Case Diagram Sistem Informasi Geografis Apotek

\section{Activity Diagram Login}

Dalam activity diagram login ini, menjelaskan urutan aktivitas yang harus dilakukan oleh pengguna (user) saat melakukan login.

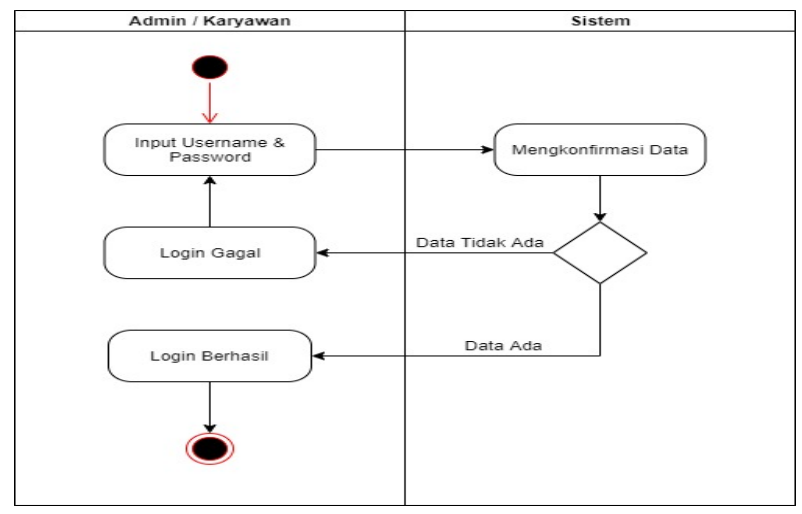

Gambar 4. Activity Diagram Login 
3. Activity Diagram Apotek

Dalam activity diagram apotek ini, menjelaskan urutan aktivitas yang harus dilakukan oleh pengguna (user) saat mengelola data apotek.

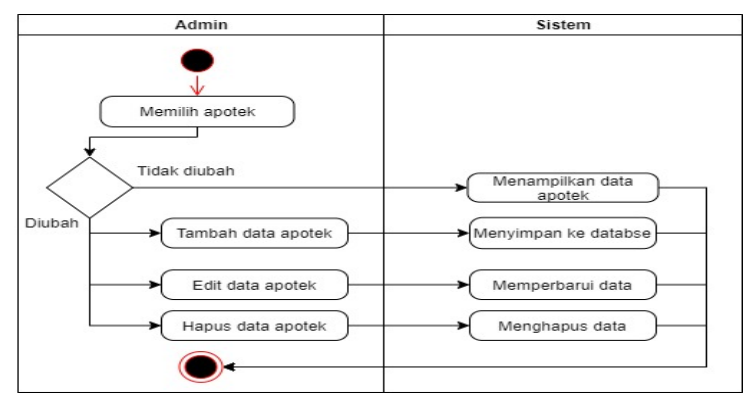

Gambar 5. Activity Diagram Apotek

4. Activity Diagram Karyawan

Dalam activity diagram karaywan ini, menjelaskan urutan aktivitas yang harus dilakukan oleh pengguna (user) saat mengelola data karyawan.

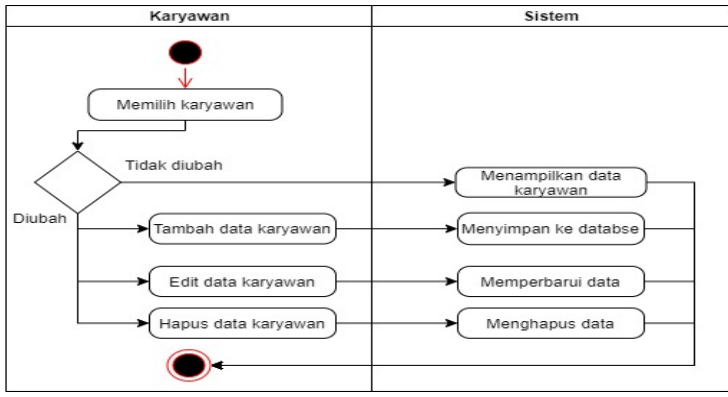

Gambar 6. Activity Diagram Karyawan

5. Activity Diagram Obat

Dalam activity diagram obat ini, menjelaskan urutan aktivitas yang harus dilakukan oleh pengguna (user) saat mengelola data obat.

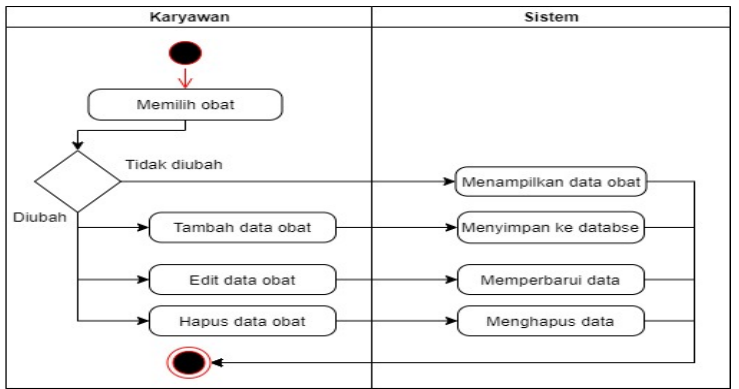

Gambar 7. Activity Diagram Obat

6. Activity Diagram Pencarian

Dalam activity diagram pencarian ini, menjelaskan urutan aktivitas yang harus dilakukan oleh pengguna (user) saat melakukan pencarian apotek.

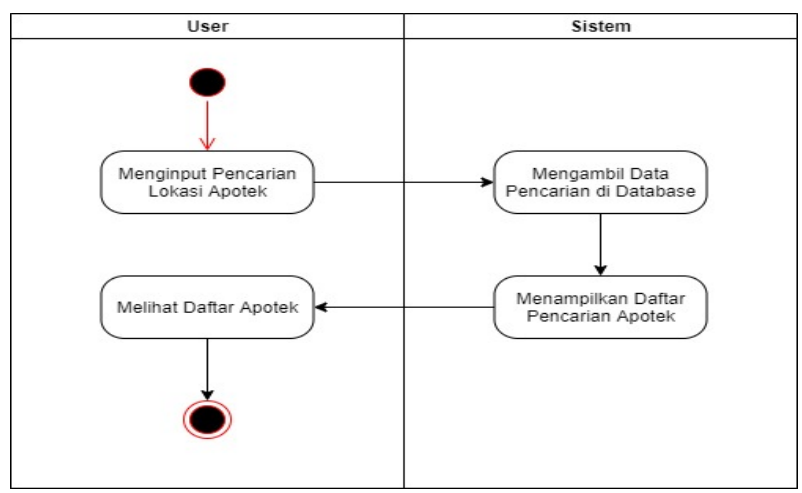

Gambar 8. Activity Diagram Pencarian

Nur Rachmat Fajar Ramadhani, Copyright @ 2020, BITS | Page 145 


\section{Activity Diagram Logout}

Dalam activity diagram logout ini, menjelaskan urutan aktivitas yang harus dilakukan oleh pengguna (user) saat melakukan logout.

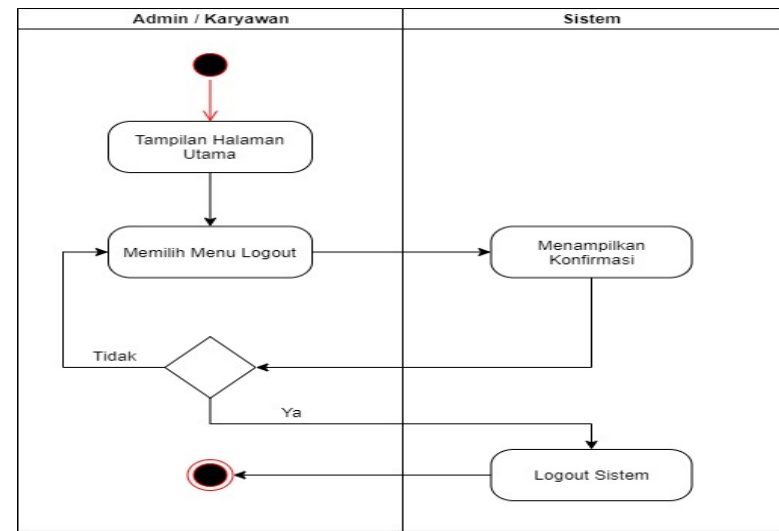

Gambar 9. Activity Diagram Logout

8. Sequence Diagram Login

Pada sequence diagram login ini, menerangkan serangkaian hubungan yang terjadi antara aktor dan objekobjek serta kelas objek pada saat pengguna (user) atau aktor ingin melakukan login.

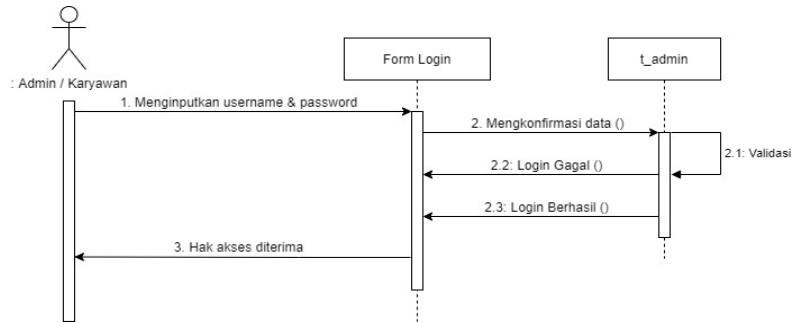

9. Sequence Diagram Apotek

Gambar 10. Sequence Diagram Login

Pada sequence diagram Apotek ini, menerangkan serangkaian hubungan yang terjadi antara aktor dan objekobjek serta kelas objek pada saat pengguna (user) atau aktor ingin mengelola data apotek.

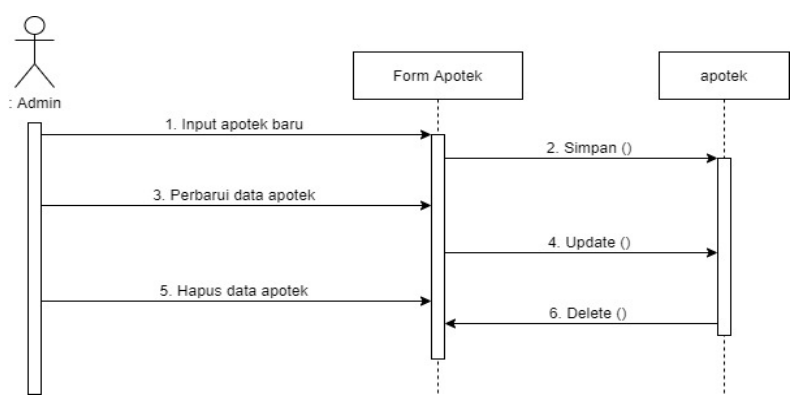

Gambar 11. Sequence Diagram Apotek

10. Sequence Diagram Karyawan

Pada sequence diagram karyawan ini, menerangkan serangkaian hubungan yang terjadi antara aktor dan objekobjek serta kelas objek pada saat pengguna (user) atau aktor ingin mengelola data karyawan.

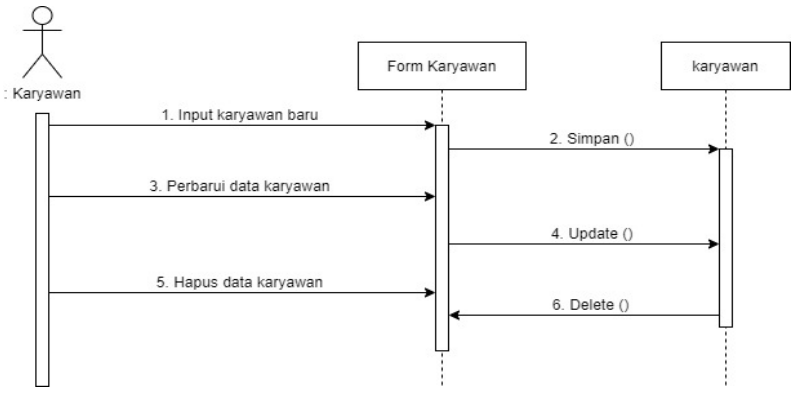

Gambar 12. Sequence Diagram Karyawan 


\section{Sequence Diagram Obat}

Pada sequence diagram obat ini, menerangkan serangkaian hubungan yang terjadi antara aktor dan objek-objek serta kelas objek pada saat pengguna (user) atau aktor ingin mengelola data obat.

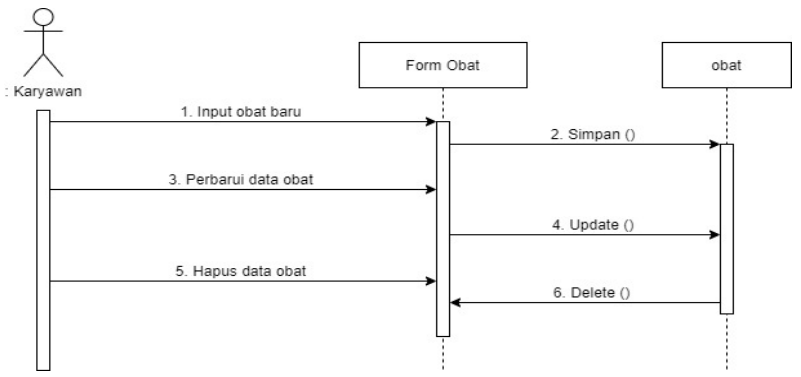

Gambar 13. Sequence Diagram Obat

12. Sequence Diagram Pencarian

Pada sequence diagram pencarian ini, menerangkan serangkaian hubungan yang terjadi antara aktor dan objekobjek serta kelas objek pada saat pengguna (user) atau aktor ingin melakukan pencarian apotek.

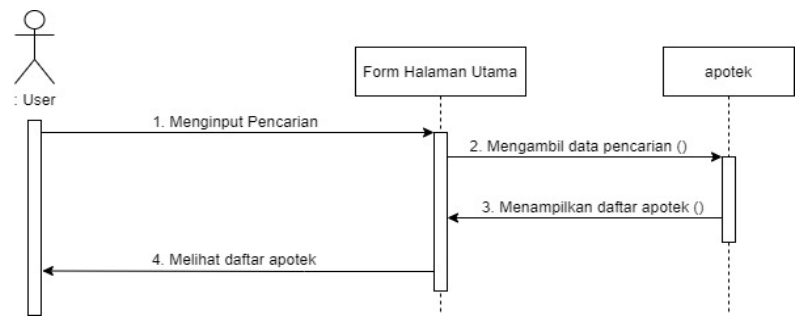

Gambar 14. Sequence Diagram Pencarian

\section{Sequence Diagram Logout}

Pada sequence diagram logout ini, menerangkan serangkaian hubungan yang terjadi antara aktor dan objekobjek serta kelas objek pada saat pengguna (user) atau aktor ingin melakukan logout.

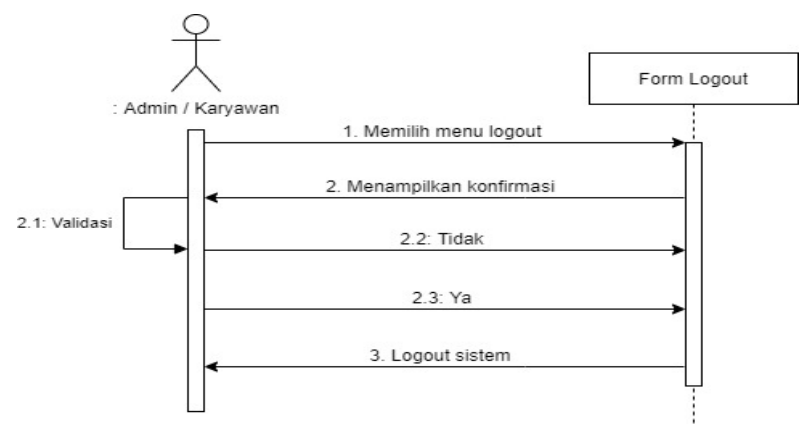

Gambar 15. Sequence Diagram Logout

\section{Class Diagram}

Pada class diagram ini, menunjukkan relasi-relasi antar tabel.
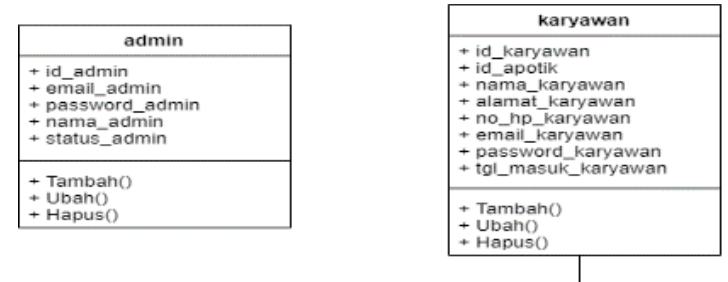

\begin{tabular}{|l|}
\hline \multicolumn{1}{|c|}{ obat } \\
\hline + id_obat \\
+ id_apotek \\
+ nama_obat \\
+ jenis_obat \\
+ stok_obat \\
+ harga_obat \\
\hline + Tambaho \\
+ Ubaho \\
+ Hapus 0 \\
\hline
\end{tabular}

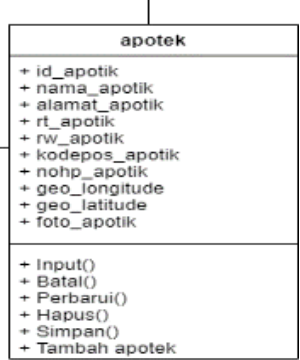

Gambar 16. Class Diagram

Nur Rachmat Fajar Ramadhani, Copyright @ 2020, BITS | Page 147 
Building of Informatics, Technology and Science (BITS)

Volume 2, No 2, December 2020 Page 141-150

ISSN 2684-8910 (media cetak)

ISSN 2685-3310 (media online)

\subsection{Implementasi Program}

Implementasi sistem informasi geografis apotek di Kotawaringin Timur berbasis web merupakan cara penerapan suatu sistem dan cara menjalankan program aplikasi sistem informasi geografis apotek di Kotawaringin Timur berbasis web.

1. Halaman Utama

Pada halaman utama menampilkan menu dan informasi, seperti gambar berikut.
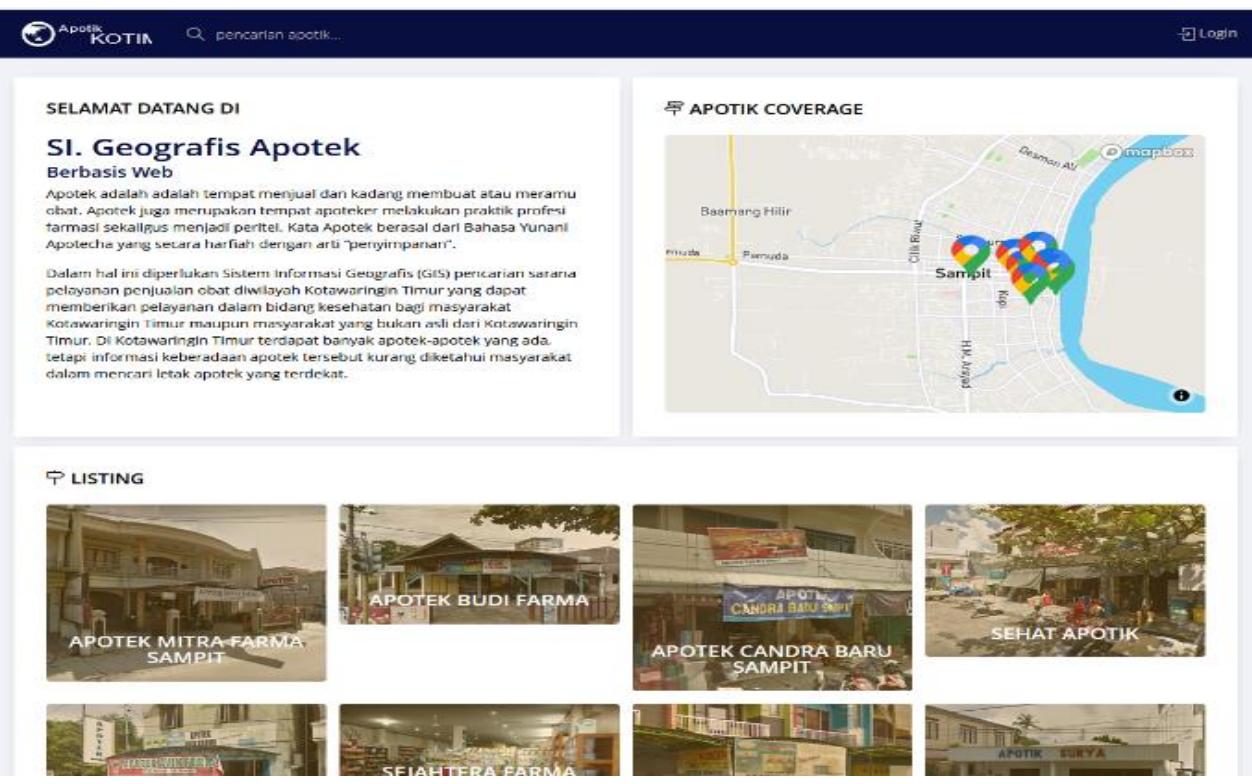

Gambar 16. Halaman Utama

2. Halaman Login

Pada halaman login ini harus memasukkan email dan password. Untuk bisa mengakses sistem informasi geografis apotek ini.

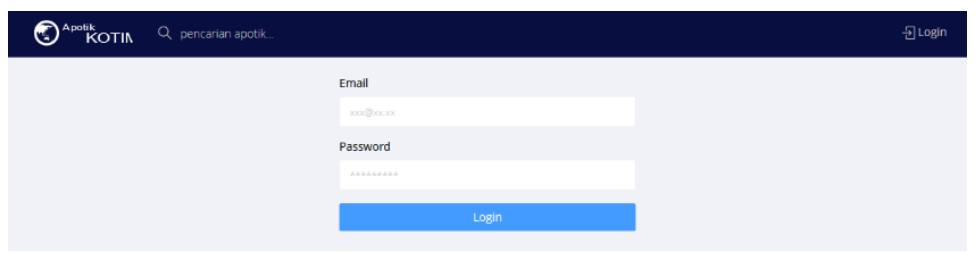

Gambar 17. Halaman Login

3. Halaman Data Karyawan

Halaman data karyawan ini merupakan menu yang hanya bisa diakses oleh karyawan. Menu ini untuk mengelola data karyawan.

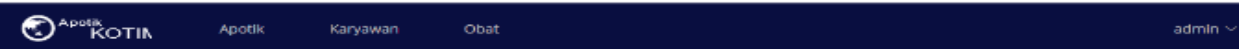

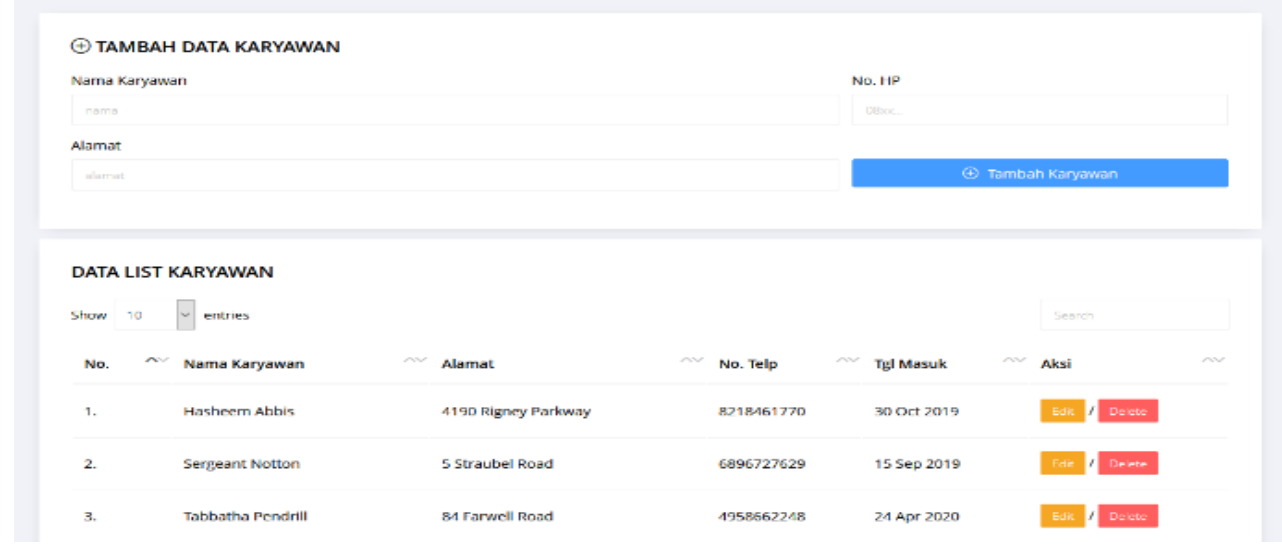

4. Halaman Data Apotek

Gambar 18. Halaman Data Karyawan

Halaman data apotek ini merupakan menu yang hanya bisa diakses oleh admin. Menu ini untuk mengelola data apotek. 
Building of Informatics, Technology and Science (BITS)

Volume 2, No 2, December 2020 Page 141-150

ISSN 2684-8910 (media cetak)

ISSN 2685-3310 (media online)

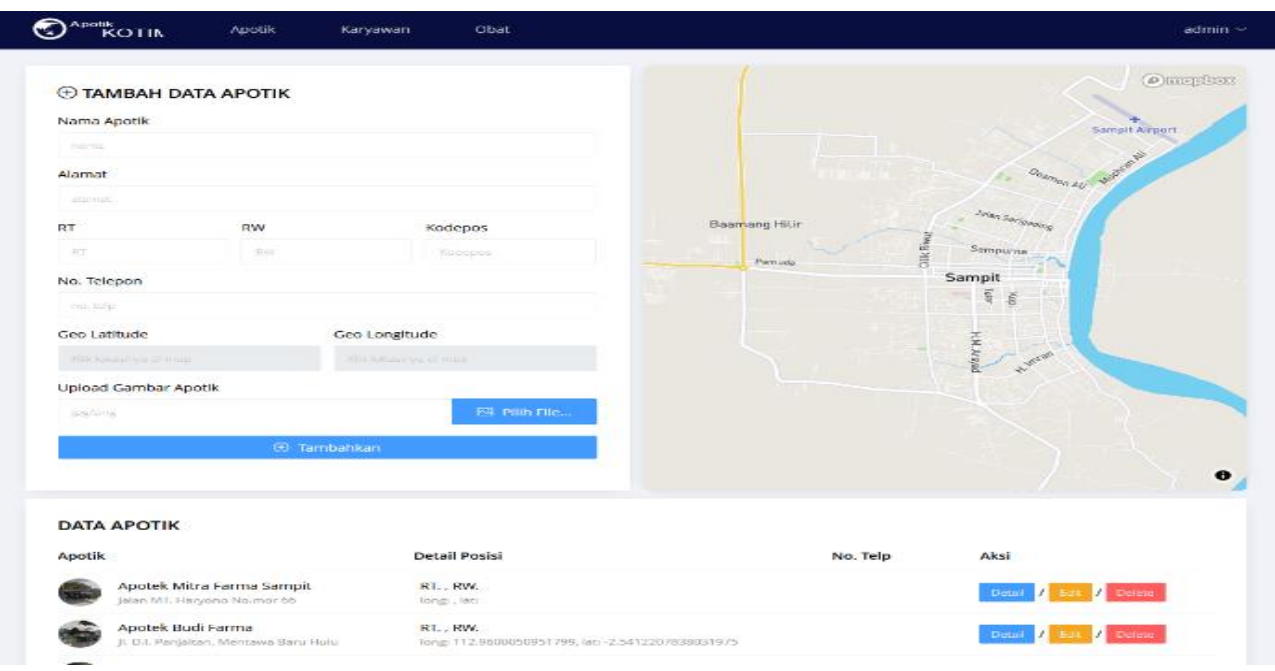

5. Halaman Data Obat

Gambar 19. Halaman Data Apotek

Halaman data obat ini merupakan menu yang hanya bisa diakses oleh karyawan. Menu ini untuk mengelola data obat.

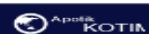
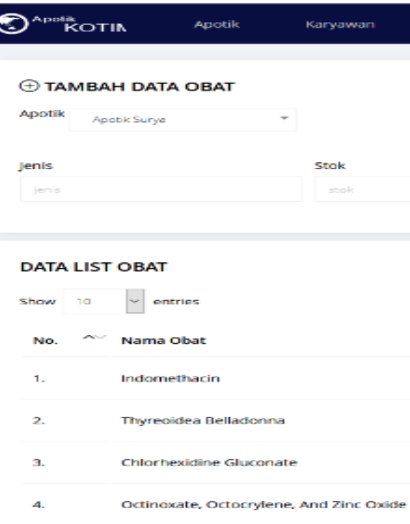

Gambar 20. Halaman Data Obat

6. Halaman Input Pencarian Apotek

Halaman ini merupakan halaman untuk pengguna (user) menginput dan mencari apotek.
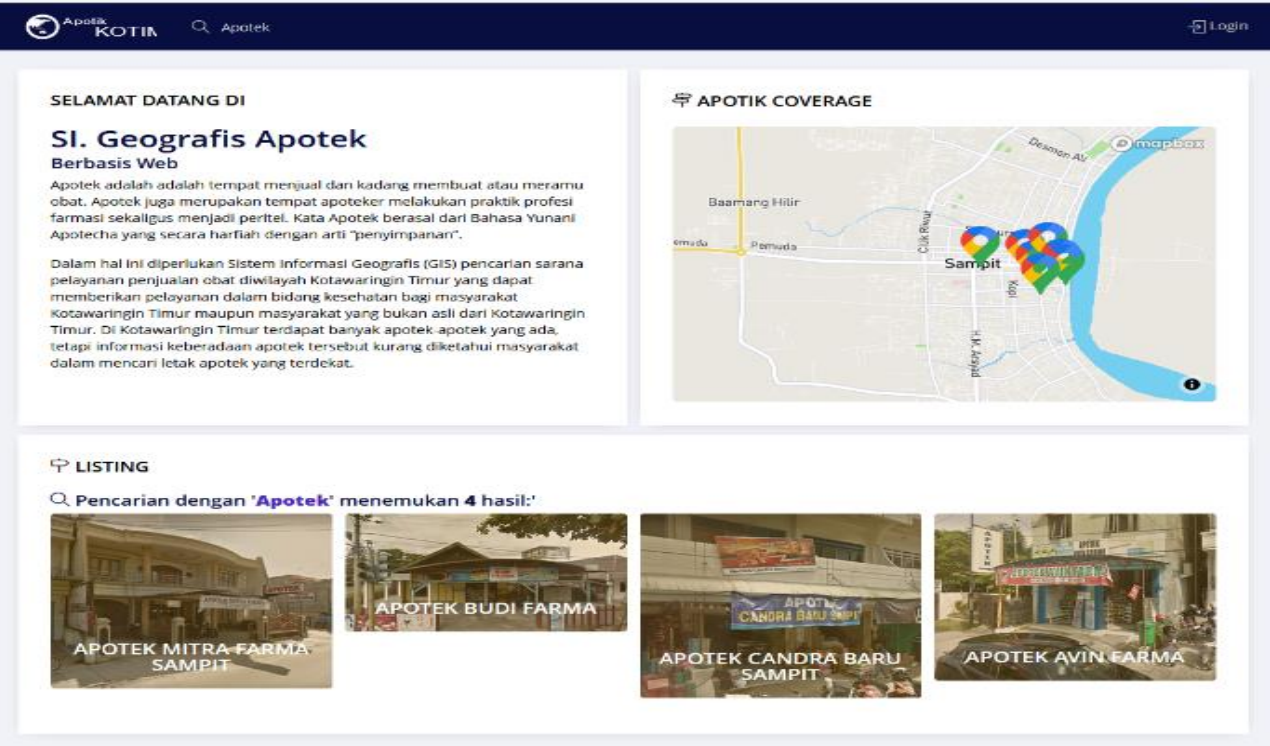

Gambar 21. Halaman Input Pencarian Apotek

7. Halaman Informasi Detail Apotek

Halaman ini imerupakan halaman untuk pengguna (user) melihat informasi detail apotek yang telah dipilih. 


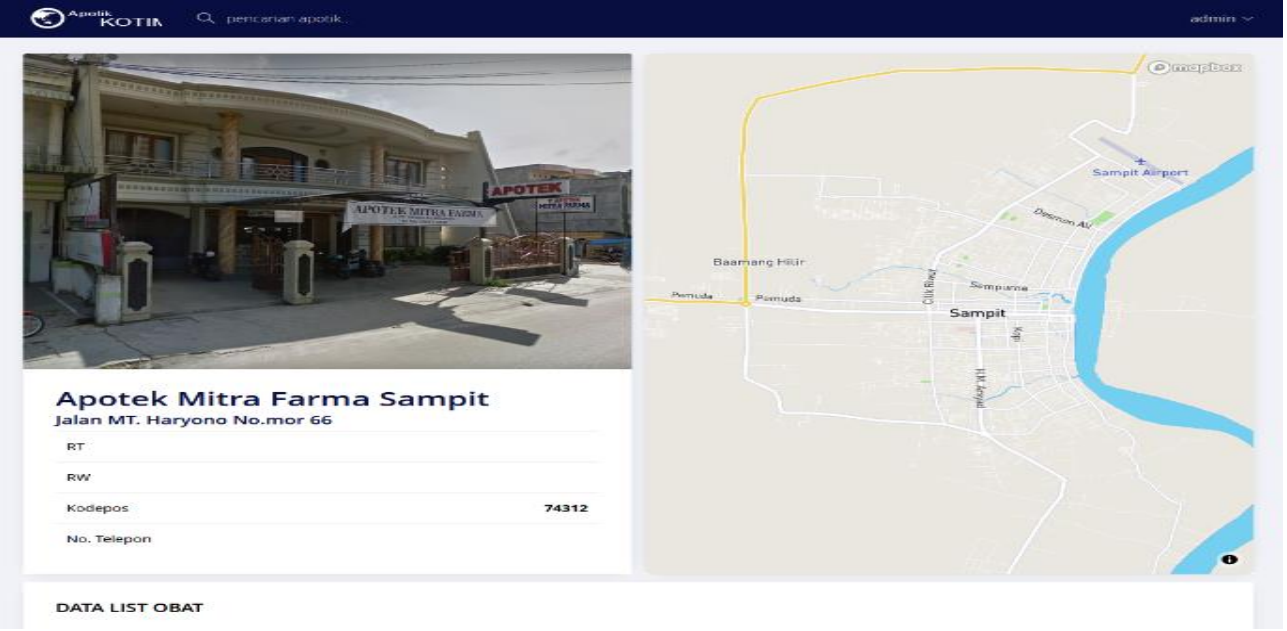

Gambar 22. Halaman Informasi Detail Apotek

\section{KESIMPULAN}

Berdasarkan dari hasil implementasi yang telah di bahas sebelumnya maka dapat di simpulkan bahwa sistem pengembangan teknologi pada satuan polisi pamong praja berbasis web ini memiliki informasi seperti pengarsipan surat, laporan gaji, absensi, cuti dan penilaian SKP yang terdata dengan baik, serta dapat menampilkan transaksi laporan data baik data keluar masuknya surat, laporan gaji, laporan absensi, laporan cuti serta data perhitungan penilaian SKP kenaikan pangkat golongan.

Adapun saran yang bisa dikembangkan untuk sistem ini yaitu bagi pengembang selanjutnya, perlu pengembangan lagi terhadap sistem yang ada agar lebih sempurna, melengkapi konten seperti gambar, berita kegiatan, dan sebagainya. Memberikan tampilan website tentang suatu kegiatan satpol, yang hanya masyarakat bisa melihat dan berkomentar di bagian kolom komentar di situs tersebut. Serta dibuatkannya saran agar saran masyarakat bisa di sampaikan pada pihak yang berwenang. Membuat program berbasis android, agar sistem lebih mudah di akses lagi melalui aplikasi android.

\section{REFERENCES}

[1] M. R. Julianti, A. Budiman, and A. Patriosa, "Perancangan Sistem Informasi Geografis Pemetaan Lokasi Apotek di Wilayah Kota Bogor Berbasis Web,” J. SISFOTEK Glob., vol. 8, pp. 13-19, 2018.

[2] M. P. Narendra, O. Skarayadi, M. Duda, and P. Adirestuti, "Analisis Tingkat Kepuasan Pelanggan Terhadap Pelayanan Di Apotek Kimia Farma Gatot Subroto Bandung,” Kartika-Jurnal Ilm. Farm., vol. 5, no. 1, pp. 31-37, 2017.

[3] I. Lutfina, "Pemanfaatan Teknologi Informasi Komunikasi Dalam Pembelajaran Fikih Di MTsN Tunggangri Kalidawir Tulungagung," IAIN Tulungagung, 2018.

[4] J. Simarmata, Pengenalan Teknologi Komputer dan Informasi. Yogyakarta: Andi, 2006.

[5] "Apakah sistem informasi itu?," School of Information Systems.

[6] J. Hutahaean, Konsep Sistem Informasi. Deepublish, 2018.

[7] Kholil, "Pemanfaatan Sistem Informasi Geografis (SIG) Dalam Aplikasi Pelaporan Dan Pelacakan Kejahatan Berbasis Android," $J$ Teknol. Inf. Dan Komun., vol. 6, no. 1, pp. 51-58, 2017.

[8] D. Setyawan, A. L. Nugraha, and B. Sudarsono, "Analisis Potensi Desa Berbasis Sistem Informasi Geografis (Studi Kasus: Kelurahan Sumurboto, Kecamatan Banyumanik, Kabupaten Semarang),"J. Geod. Undip2, vol. 7, no. 4, 2018.

[9] F. H. Siregar, Y. H. Siregar, and Melani, "Perancangan Aplikasi Komik Hadist Berbasis Multimedia," J. Teknol. Inf., vol. 2, no. 2, 2018. 